\title{
O Uso pedagógico do Programa Nacional de Tecnologia Educacional, nas Escolas Públicas Municipais
}

\author{
Raimundo Edilberto Moreira Lopes ${ }^{\text {; }}$ Osvaldo Arsênio Vilalba ${ }^{2}$
}

\begin{abstract}
Resumo: No Brasil, os primeiros laboratórios de tecnologias para informática do Proinfo (Programa Nacional de Informática na Educação) foram efetivados escolas públicas municipais à partir de 1997.0 presente estudo objetivou discutir as contribuições da utilização do Proinfo nas escolas públicas, como ferramenta pedagógica inovadora no processo ensino-aprendizagem, nas escolas públicas de Banabuiú. A pesquisa envolveu 12 escolas de ensino fundamentais do município, sendo 3 na zona urbana e 9 na zona rural do município. A coleta de dados foi realizada através de um questionário contendo questões fechadas, respondidos por alunos, professores e gestores, funcionários e familiares dos alunos. Após análise dos dados, constatou-se que, nem todas as escolas possuem uma infra-estrutura apropriada para laboratórios de informática; Muitos professores ainda têm receio quanto à utilização do computador em sala de aula. Que os mesmos carecem de maior treinamento na área didática para lidarem com as novas tecnologias. Que utilizam-se pouco do aparato de recursos em termos computacionais em suas aulas, mesmo conhecendo que há uma demanda latente dos alunos quanto a sua incorporação como recurso didático. Concluiu-se pois, que ainda é relativamente grande o déficit quanto a formação de professores para o trabalho em ambientes informatizados. Que a informática para uso em sala de aula, não tem sido vivenciada da forma como foi originalmente concebido no programa e que, portanto, o uso regular e corriqueiro dos laboratórios de informática enquanto recurso pedagógico, ainda não alcançou a sua meta.
\end{abstract}

Palavras-chave: laboratório de informática, Internet, ensino-aprendizagem

\section{The Pedagogic use of the National Educational Technology Program in Municipal Public Schools}

\begin{abstract}
In Brazil, the first laboratories of technologies for informatics of Proinfo (National Programme for Informatics in Education) were hired public schools starting from 1997. This study discusses the contributions of the use of Proinfo in public schools as an innovative educational tool in teaching-learning process in public schools from Banabuiú. The research involved 12 basic schools of the municipality, and 3 in the urban area and 9 in rural municipality. Data collection was conducted through a questionnaire with closed questions, answered by students, teachers and administrators, employees and families of students. After analyzing the data, it was found that not all schools have an appropriate infrastructure for computer labs; Many teachers still have fears about the use of computers in the classroom. That they need further training in the teaching area to deal with new technologies. That just are used of the apparatus of computational resources in terms in their classes, even knowing that there is a latent demand of students and their incorporation as a teaching resource. It was concluded therefore that is still relatively large deficit as the training of teachers to work in computerized environments. That informatics for use in the classroom, has not experienced the way it was originally designed in the program and, therefore, regular and frequent use of computer labs while teaching resource, not yet reached its goal.
\end{abstract}

Keywords: computer lab, Internet, teaching-learning

\footnotetext{
${ }^{1}$ Mestre e Doutor em Ciências da Educação pela Universidad San Carlos. Especialista em Química e Biologia pela Universidade Regional do Cariri - URCA (2006); Especialista em Gestão Escolar pela Universidade do Estado de Santa Catarina - UDESC (2006); graduado em Pedagogia pela Universidade Estadual Vale do Acaraú - UVA (2002); graduado em Ciências/Química e Biologia pela Universidade Estadual do Ceará - UECE (2002). E-mail: beto.ce@ hotmail.com;

${ }^{2}$ Programa de Pós-Graduação da Universidad San Carlos - PY. E-mail: oavillalba @ hotmail.com.
} 
Introdução

O ingresso da informática nas escolas públicas, trás em seu arcabouço conceitual uma nova maneira de pensar o ensino. Também representa uma nova perspectiva de trabalho para os docentes, implicando num repensar de métodos, técnicas e habilidades na sua práxis cotidiana.

É uma nova modalidade de transmissão de conhecimentos que abre novas perspectivas em termos de pesquisa educacional, porém, exigindo um envolvimento de todos os atores a serem beneficiados. Desde os próprios alunos, professores, gestores, funcionários das escolas, até a própria família dos alunos. Nesse sentido, criar e estimular projetos para uso de computadores, com finalidade educativa, muito certamente virão a contribuir para uma melhoria do processo ensino-aprendizagem.

Alguns resultados de ações nesta direção, têm se mostrado significativos para o desenvolvimento cognitivo de crianças e jovens em todo o mundo. Por outro lado, alguns projetos não passam de uma estratégia de autopromoção dos gestores, pois se não houver um real comprometimento dos professores e gestores, integrado aos interesses educacionais, tenderá ao fracasso.

Apresentamos neste trabalho os resultados de uma pesquisa realizada nas escolas públicas municipais de Banabuiú-Ceará. A pesquisa envolveu cinco segmentos de cada escola: alunos, funcionários, representantes famílias, professores e núcleo gestor.

O Programa Nacional de Tecnologia Educacional (PROINFO), pioneiro na distribuição de computadores, recursos multimídia e conteúdos educacionais nas escolas públicas do país. Buscamos compreender através dessa pesquisa como acontece de fato a uso dos recursos tecnológicos disponibilizados nas instituições de ensino.

A necessidade de metodologias diversificadas nas escolas se tornou um tema que exige muito estudo para o melhor direcionamento de políticas públicas destinadas ao processo ensino aprendizagem.

As escolas públicas do município de Banabuiú dispõem de laboratório de Informática do ProInfo. A presente pesquisa surgiu com o intuito de avaliar o referido Programa nas Escolas públicas municipais. Buscou-se compreender a utilização do ProInfo e a sua possibilidade como ferramenta pedagógica. Essa foi a motivação principal do presente estudo.

O uso didático-pedagógico das novas Tecnologias da Informação e da Comunicação no dia-adia acadêmico, tem sido estimulado pelo programa Proinfo do Governo Federal. Este também é associado a distribuição de equipamentos tecnológicos às escolas, bem como a oferta de conteúdos e determinados recursos digitais e de multimídia, disponibilizados nos sites governamentais e de domínio público, bem como pelo Banco Internacional de Objetos Educacionais. 
Portanto, faz-se necessária uma avaliação, capaz de conhecer quais as contribuições que traz a utilização do Programa Nacional de Tecnologia Educacional, para as escolas públicas municipais, como ferramenta pedagógica inovadora, no processo ensino aprendizagem.

\section{A Tecnologia a Serviço da Educação e a sua Contribuição no Sistema Educativo.}

O crescimento e o desenvolvimento de uma nação é sempre marcado pela nossa capacidade de raciocinar. Considerando o período da descoberta do fogo até o contemporaneidade, percebemos que a tecnologia foi sempre a responsável pelo desenvolvimento de um povo. O domínio do fogo, da pedra do ouro, por exemplo, são formas de tecnologias de um certo período histórico. A autora KENSKI define tecnologia sendo “(...) o conjunto de conhecimentos e princípios científicos que se aplicam ao planejamento, à construção e a à utilização de um equipamento em um determinado tipo de atividade, chamamos de "tecnologia". (KENSKI, 2012, p. 24)

Ainda de acordo com o pensamento da mesma autora "As tecnologias são tão antigas quanto a espécie humana". De acordo com a autora a tecnologia sempre esteve presente na nossa sociedade e esta evolui a medida que existe a necessidade de evolução da sociedade.

Atualmente os países desenvolvidos são os países que tem o domínio da tecnologia., Segundo LYOTARD, apud KENSKI (2012, p. 18), “A única chance que o homem tem para conseguir acompanhar o movimento do mundo é adaptar-se à complexidade que os avanços tecnológicos impõem a todos, indistintamente". Estamos, de certa forma, conectados e mais dependente da tecnologia com o passo dos tempos.

Essa dependência está presente em todos os setores, principalmente na educação, que a cada dia se faz necessário a criação de novas estratégias de ensino. O professor na contemporaneidade, deve conhecer e manusear com habilidade os recursos tecnológicos possíveis à construção do conhecimento. A autora KENSKI, contribui com esse pensamento afirmando que,

$\mathrm{Na}$ atualidade, o surgimento de um novo tipo de sociedade tecnológica é determinado principalmente pelos avanços das tecnologias digitais de comunicação e informação e pela microeletrônica. Essas novas tecnologias - assim consideradas em relação às tecnologias anteriormente existentes -, quando disseminadas socialmente, alteram as qualificações profissionais e a maneira como as pessoas vivem cotidianamente, trabalham, informam-se e se comunicam com outras pessoas e com todo o mundo (KENSKI, 2012, p. 22).

As novas tecnologias utilizadas na comunicação e os novos modos de educação a distância que estas possibilitaram apontam claramente para a necessidade de se repensar os processos da educação, não somente dos alunos, mas dos próprios professores. As formas de educação dos 
professores existentes no século XX, nas faculdades e centros universitários de educação, não são mais capazes de atender a demanda por novas tecnologias deste século. Em muitas partes do mundo, a problemática é ainda maior, pois faltam professores. Dessa forma, muitos adultos leigos enfrentam o desafio da sala de aula. Mesmo em países ricos existem dificuldades no sistema de ensino fundamental. Nos EUA, por exemplo, estima-se que um terço das aulas das $7^{\mathrm{a}}$ e $8^{\mathrm{a}}$ séries, alunos de sete a 12 anos, são ministradas por professores não especialistas (INGERSOLL, 1999 e 2004) Em algumas disciplinas, essa percentagem tende a ser mais alta, como em história e ciências. Nestas, cerca de metade das aulas são ministradas por não especialistas.

Portanto, o cenário contemporâneo da educação, aponta para uma necessidade de maneiras de desenvolvimento mais abrangentes, além de educação e formação com foco numa escola mais ampla, conectada não somente com seu contexto, mas com o mundo. Muito do desenvolvimento profissional de uma maioria de professores, deverá acontecer no próprio local de trabalho, quebrando os velhos paradigmas de um modelo de formação dada em um campi universitário. Dessa forma, um modelo mais adaptado a modernidade e as novas tecnologias disponíveis, mais abertas e a distância.

Numa ótica mais tradicional de pensar, a educação a distância sempre foi alvo de críticas, como uma opção menos requisitada, por parecer de pouca importância. Mesmo assim, grandes nomes mundiais, a exemplo de Nelson Mandela obtiveram seus diplomas graças a à educação a distância, neste caso, porque estava preso. Mesmo assim, ainda continua sendo um preconceito, particularmente entre aqueles que formulam as políticas governamentais dos países.

Mesmo com as mais tecnologias mais recentes de comunicação, que possuem um status elevado, o aprendizado aberto e/ou a distância ainda é visto como de menor valor (MOON, 2000). Os programas que utilizam tecnologias avançadas tendem a ter um custo-benefício menor do que outras alternativas. Também é importante ressaltar que as novas tecnologias que apareceram á partir do computador e da internet, certamente agregam um maior valor e qualidade às aulas, mas apenas se o professor dominar tal tecnologia. Caso contrário, será somente mais um adereço, sem uma função educativa ou crítica.

As novas tecnologias mudaram as comunicações. Fornecem modos mais criativos e motivadores de apresentar as informações, bem como fornecem maiores oportunidades de interação (LEACH e MOON, 2002). A mobilidade exponencial dessas tecnologias, está acenando com possibilidades, antes impensáveis, inclusive para alunos que residem em lugares afastados, geralmente em zonas rurais. Embora politicamente pareçam custar a emitir respostas, essas novas possibilidades, quando implementadas em cumprimento dos seus princípios básicos, tendem a dar respostas positivas (MOON et al., 2005)..

As novas tecnologias utilizadas na comunicação, oferecem realmente uma gama muito mais rica de possibilidades interativas. Essas associadas a nova geração de celulares, podem permitir 
debates em grupos, discussões entre professores e alunos, melhorar a informação na escola, dentre outras possibilidades acadêmicas e relacionais.

Em resumo, um programa inovador, necessita prever e planejar a preparação dos professores, de maneira a permitir o ótimo aproveitamento dos envolvidos.

Atualmente as novas tecnologias disponíveis, parecem ser o caminho que se precisa trilhar para chegar a uma educação com mais qualidade e mais sintonizada com o conhecimento globalizado.

Mas é preciso nos indagar: se sabemos o caminho, qual a direção a seguir?; a disponibilidade de conteúdos disponíveis na rede mundial de computadores é muito vasta, quais os conteúdos que devemos utilizar? São todos confiáveis e seguros?; quais os objetivos a alcançar com essas ferramentas; quais estratégias utilizar, quando as mesmas já estão inclusive, disponíveis nos telefones móveis, cada dia mais acessíveis a um número maior de usuários?

Na sequência, discutiremos um pouco mais sobre esses questionamentos.

\section{Histórico do Programa Nacional de Tecnologia Educacional (PROINFO)}

O ProInfo é um Programa vinculado à Secretaria de Educação a Distância (SEED), do Ministério da Educação (MEC) que foi criado através da portaria n ${ }^{\circ} 522$ em 04 de abril de 1997, sob a coordenação de Cláudio Salles. Inicialmente sendo chamado de Programa Nacional de Informática na Educação, com a finalidade de levar a tecnologia como ferramenta de apoio pedagógico nas redes do ensino público fundamental e médio.

Em 12 de dezembro de 2007, através do decreto lei nº 6.300, o ProInfo passou a ser Programa Nacional de Tecnologia Educacional, sendo que o principal objetivo do Programa nessa nova nomenclatura, é promover o uso das tecnologias da informação e comunicação, como ferramenta pedagógica nas redes públicas da educação básica, disponibilizando para as instituições de ensino computadores, recursos multimídia e conteúdos educacionais.

Em cada unidade da federação existe uma Coordenação Estadual e os Núcleos de Tecnologia Educacional - NTE, com infraestrutura de comunicação e informática, local adequado para receber os professores e especialistas em tecnologias educacionais.

Até 2006 esse programa já distribuiu, 147.355 (cento e quarenta e sete mil e trezentos e cinquenta e cinco) microcomputadores, somando um valor de 239.021.464,00 (duzentos e trinta e nove bilhões, vinte e um milhões e quatrocentos e sessenta e quatro reais), beneficiando assim 5.564 (cinco mil, quinhentos e sessenta e quatro) municípios alcançando 14.521 (quatorze mil e quinhentos e vinte e uma) entidades, chegando a 507.431 (quinhentos e sete mil e quatrocentos e trinta e um) 
professores e a 13.366 .829 (treze bilhões, trezentos e sessenta e seis milhões e oitocentos e vinte e nove) alunos.

O custo médio de cada equipamento do programa é 1.622,08 (mil seiscentos e vinte e dois reais e oito centavos). A média de aluno por equipamentos até o ano de 2006 é 90,71. Mesmo com todo empenho do Governo percebemos uma média muito alto na relação aluno $\mathrm{X}$ quantidade de equipamento. Apenas 9,07\% dos alunos, e 13,43 dos professores é potencialmente atingido pelo Programa.

Mesmo com essa média baixa o programa implanta 201.657 (duzentos e um mil e seiscentos e cinquenta e sete) laboratórios de informática nas escolas brasileiras somando um valor de 3.793 .000 (três milhões e setecentos e noventa e três mil) microcomputadores.

Até 2006 o programa alcança 11,85\% das escolas na distribuição dos equipamentos e garantindo $11,54 \%$ conectadas a rede mundial de computadores.

Com as informações atualizadas, apenas até o ano de 2006, percebemos o grande volume de recursos públicos destinados ao Programa e acreditamos que em poucos anos todas as escolas do nosso pais serão atendidas com as ferramentas do ProInfo.

O município ou o estado, para participar do ProInfo, deve seguir basicamente três passos: a Adesão, o Cadastro e a Seleção das escolas. É disponível no site do ProInfo as orientações bem detalhadas para alcançar os três passos.

No primeiro passo que é a adesão, o município ou estado assume o compromisso com as diretrizes do programa, imprescindível para o recebimento dos laboratórios. Para isso deve-se fazer o download do termo de adesão, assinar e enviar ao MEC com a documentação exigida.

O segundo passo é o cadastro do prefeito no site do programa, onde será solicitado um usuário e senha, criado pelo responsável pelos dados, que permite que o próximo passo, a seleção de escolas, seja efetuado.

O terceiro e último passo é a seleção das escolas, que é feita no sistema, onde já existem escolas pré-selecionadas de acordo com os critérios adotados pelo MEC/SEED.

No programa, MEC/SEED compra, distribui e instala laboratórios de informática nas escolas públicas de educação básica. Os governos locais (prefeituras e governos) participam na contrapartida de providenciar a infraestrutura das escolas, indispensável para que elas recebam os computadores.

A distribuição é dividida em ProInfo rural e PorInfo Urbano, sendo necessário garantir alguns critérios, a saber:

ProInfo rural, destinado a escolas de Ensino Fundamental com mais de 50 alunos, com energia elétrica e sem laboratório de informática. Para essa distribuição, temos a seguinte composição:1 servidor; 4 estações; 5 Monitores LCD; 1 Impressora Jato de Tinta; Linux Educacional; Garantia de 3 anos; Mobiliário: 5 mesas para computador, 5 cadeiras e 1 mesa para impressora. 
A contrapartida do município ou estado: Sala com Segurança (grades nas portas e janelas); Uma tomada de pino duplo para o laboratório.

O proInfo urbano é destinado para as Escolas de Ensino Fundamental do $6^{\circ}$ ao $9^{\circ}$ anos, com mais de 50 alunos, onde tenha energia elétrica e sem laboratório de informática. Para essa distribuição, temos a seguinte composição: 1 servidor de rede; 15 estações para o laboratório de informática; 2 estações para área administrativa; Monitores LCD; 1 Roteador Wireless; 1 Impressora Laser; 1 Leitora de Smart Card; Sistema Linux Educacional; Garantia de 3 anos; Não acompanha mobiliário.

A contrapartida do município ou estado: Sala com Segurança (grades nas portas e janelas); Mobiliário para acomodar 18 terminais e 1 impressora;

Com essas ações e políticas de Informática na Educação, realizadas no Brasil, é possível afirmar que tal experiência pode chegar às diversas instituições de ensino do País

Para que cada município e estado possa participar efetivamente de todas as etapas do programa, é necessário a disponibilidade de profissional lotado na Secretaria de Educação para acompanhar todas as liberações do Governo Federal para as unidades de ensino.

\section{O ProInfo em Banabuiú}

Atualmente o município de Banabuiú tem 22 unidades de ensino cadastradas no INEP (Instituto Nacional de Estudos e Pesquisas Educacionais Anísio Teixeira), autarquia do Ministério da Educação do Brasil. Das 22 unidades de ensino do município, 12 são Escolas de Ensino Fundamental e 10 são Pré-escola/Creche.

A primeira experiência em laboratório de informática nas escolas em Banabuiú aconteceu na sede do município em 2001, quando a escola Centro Educacional Municipal Celestino de Sousa recebeu da Empresa Telemar, um laboratório de informática com 10 computadores conectados a internet.

A partir de 2009 as escolas Públicas Municipais de Banabuiú passaram a receber os laboratórios pelo ProInfo. As primeiras escolas foram atendidas no dia 05 de outubro de 2009, sendo que atualmente todas as escolas de ensino fundamental já receberam o laboratório de informática conectados a internet.

Em resumo, embora a mudança pedagógica seja o objetivo maior das ações deste projeto de informática, nem sempre os resultados obtidos são suficientes para sensibilizar ou mudar o sistema de educação vigente como um todo. Este estudo teve o propósito de discutir a forma como os envolvidos percebem as mudanças na educação, à partir do ProInfo em Banabuiú. 
Certamente a entrada e utilização dos recursos computacionais na escola tiveram o mérito de passar a informática na educação do estado de não ter essa tecnologia disponível, para o estado atual. Com possibilidades potenciais diversas, mas ainda há muito o que se discutir à partir dos resultados da mesma.

Embora muitas das questões envolvidas na implantação da informática, nas escola públicas pareçam mais claras hoje, as ações do passado não foram necessariamente pensadas para o grande desafio que temos hoje. E mesmo com o aparato atual, as ações parecem incipientes ante a demanda por mudanças no sistema de ensino brasileiro e, por que não dizer, em todo o mundo. Mas uma coisa parece ser consenso entre os autores. Há que ter professores preparados para um projeto exitoso.

Não basta um material de primeiro mundo, uma tecnologia de ponta, se não se está preparado para lidar com a mesma. Portanto sem efetivação das propostas de qualificação dos educadores, previstas no projeto, dificilmente se deve esperar uma mudança capaz de reverter, de forma rápida e positiva a, situação da educação no país.

\section{Método}

O presente trabalho é um estudo exploratório, descritivo, transversal, com abordagem quantitativa, realizado no Município de Banabuiú, Estado do Ceará - Brasil. Trata-se de um município pertencente a Mesorregião dos Sertões cearenses, que possui uma população de 17.842 habitantes, ocupando uma área em torno de 1.080.329 quilômetros quadrados (IBGE, 2014). É o $19^{\circ}$ município com maior população entre os municípios dos sertões do Ceará.

O universo da pesquisa abrangeu todas as doze escolas de Ensino Fundamental das zonas urbana e rural do Município de Banabuiú-Ceará, a saber: Centro Educacional Municipal Celestino de Sousa; EEF Ernesto de Sousa Nobre; EEF Paulo Sarasate; EEF Elias Ferandes; EEF João Ferreira da Cunha; EEF José Antonio de Oliveira; EEF Irmã Ruth Távora; EEF Raul Urquidi; EEF Vanderlei da Silva Aguiar; EEF Abel Ferreira Lima; EEF Albertina Maia Ferreira; EEF Coronel Pergentino Ferreira.

As informações foram coletadas junto à clientela atendida por cada escola (pais, alunos) e profissionais da educação (funcionário, professor e gestor). A ação distribuiu-se em diferentes etapas, permitindo que cada parte analisada opinasse, seja na forma escrita ou oral.

Utilizou-se questionários que foram aplicados aos gestores, professores, funcionários alunos e representantes da família, com enfoque nos objetivos da pesquisa. Os mesmos foram analisados e confrontados com a literatura especializada na temática, para processo de conclusão. 
A amostra contou com alguns dos seguimentos das Escolas das turmas de $5^{\circ}$ e $9^{\circ}$ anos, assim distribuídos: 24 membros do núcleo gestor, 25 professores, 22 funcionários, 124 alunos e 23 representantes familiares. A amostra tomada envolveu 100\% dos membros do núcleo gestor, $100 \%$ dos professores do $5^{\circ}$ ano, $25 \%$ dos professores do $9^{\circ}$ ano, $20 \%$ dos funcionários, $30 \%$ dos alunos matriculados nas turmas de $5^{\circ}$ e $9^{\circ}$ anos e $10 \%$ dos representantes familiares.

A educação no município tem sido bem gerida. Em avaliação recente, promovida pela Secretaria Estadual de Educação, todas as doze escolas municipais de Banabuiú ficaram com nota 10 pelo nível de proficiência como resultado do Sistema Permanente de Avaliação da Educação Básica do Ceará (Spaece)/ALFA. Isso coloca o município na melhor posição da região.

Banabuiú ficou com 201.1 pontos em proficiência, garantindo espaço entre os 150 melhores municípios do Estado do Ceará. As escolas, Celestino de Sousa e Albertina Maia Ferreira, distrito de Rinaré, foram premiadas pelo $2^{\circ}$ ano por qualidade no ensino e desempenho dos estudantes.

Inicialmente foi realizado contato com o Secretário de Educação Municipal para a tomada de decisão quanto as instituições e, para solicitar autorização para o estudo de campo.

Em seguida foram selecionados 10 (dez) universitários do curso de Pedagogia, que passaram a integrar a equipe de pesquisadores, sob a orientação do coordenador do estudo, professor Raimundo Edilberto Moreira Lopes. A seleção dos pesquisadores se deu através de análise curricular e produção textual. Após o resultado da seleção, foi realizada uma reunião, onde os pesquisadores participantes foram esclarecidos da proposta do estudo e do plano de trabalho.

Os sujeitos foram entrevistados em seus locais de trabalho e estudo (escolas) e em suas residências, no caso de alguns pais e familiares.

Foram ouvidas 218 (duzentos e dezoito) pessoas dos diversos seguimentos selecionados, no período de Março a Maio de 2014.

O questionário foi construído exclusivamente para o propósito da pesquisa.

As perguntas envolveram diversos questionamentos que avaliaram desde o funcionamento e a utilização do laboratório de informática das escolas, bem como a adequação dos espaços e a disponibilização do acesso a internet, até as questões relativas às percepções dos respondentes sobre a importância do uso das novas tecnologias para a melhoria do aprendizado e da motivação para o estudo, a exemplo de: "Você conhece o laboratório de informática da sua escola? "; "Sua escola dispõe de um espaço físico adequando para a instalação do laboratório de informática?”; "O laboratório de informática de sua Escola está em funcionamento?”; “O laboratório de informático de sua escola está conectado a rede de Internet?"; "Em sua opinião, o fato de utilizar a tecnologia para o estudo, trouxe alguma melhora na sua aprendizagem?". 


\section{Resultados e Discussões}

\section{Caracterização da amostra}

Fizeram parte desta amostra doze instituições de ensino públicas municipais, envolvendo diretamente 218 respondentes entre Alunos do $5^{\circ}$. ao $9^{\circ}$. anos, professores, gestores escolares, funcionários e pais, de acordo com a tabela a seguir.

TABELA 1 - Escolas que fizeram parte da amostra e número de respondentes por segmentos. Banabuiú, 2014.

\begin{tabular}{l|l|l|c|c|c|c|c|}
\hline \multicolumn{1}{|c|}{ Escola } & Zona & Alunos & $\begin{array}{c}\text { Profes } \\
\text {-sores }\end{array}$ & $\begin{array}{c}\text { Gesto- } \\
\text { res }\end{array}$ & $\begin{array}{c}\text { Funcio- } \\
\text { nários }\end{array}$ & Pais \\
\hline $\mathbf{1}$ & $\begin{array}{l}\text { Centro Educacional Municipal } \\
\text { Celestino de Sousa. }\end{array}$ & Urbana & 14 & 2 & 2 & 1 & 2 \\
\hline $\mathbf{2}$ & EEF Abel Ferreira Lima & Rural & 9 & 2 & 2 & 2 & 2 \\
\hline $\mathbf{3}$ & EEF Albertina Maia Ferreira & Rural & 14 & 2 & 2 & 2 & 2 \\
\hline $\mathbf{4}$ & $\begin{array}{l}\text { EEF Coronel Pergentino } \\
\text { Ferreira }\end{array}$ & Rural & 10 & 2 & 2 & 2 & 2 \\
\hline $\mathbf{5}$ & EEF Elias Fernandes & Rural & 12 & 3 & 2 & 2 & 2 \\
\hline $\mathbf{6}$ & EEF Ernesto de Sousa Nobre. & Rural & 11 & 2 & 2 & 2 & 2 \\
\hline $\mathbf{7}$ & $\begin{array}{l}\text { EEF Irmã Ruth Távora de } \\
\text { Albuquerque }\end{array}$ & Urbana & 15 & 2 & 2 & 2 & 2 \\
\hline $\mathbf{8}$ & EEF João Ferreira da Cunha & Rural & 4 & 2 & 2 & 2 & 2 \\
\hline $\mathbf{9}$ & EEF José Antonio de Oliveira & Rural & 11 & 2 & 3 & 2 & 2 \\
\hline $\mathbf{1 0}$ & EEF Paulo Sarasate. & Rural & 9 & 2 & 2 & 2 & 2 \\
\hline $\mathbf{1 1}$ & EEF Raul Urquidi & Urbana & 5 & 2 & 2 & 2 & 2 \\
\hline $\mathbf{1 2}$ & EEF Vanderlei da Silva Aguiar & Rural & 10 & 2 & 1 & 1 & 1 \\
\hline TOTAL POR SEGMENTO & & $\mathbf{1 2 4}$ & $\mathbf{2 5}$ & $\mathbf{2 4}$ & $\mathbf{2 2}$ & $\mathbf{2 3}$ \\
\hline TOTAL & & & & $\mathbf{2 1 8}$ & & \\
\hline
\end{tabular}

Fonte: Documentos das escolas.

A pesquisa abrangeu três escolas da Zona Urbana (25\%) e nove escolas da Zona Rural (75\%) de Banabuiú-CE.

Os respondentes, num total de 218 sujeitos, foram extratificados da seguinte maneira: 124 foram alunos (56,8\%), 25 professores do $5^{\circ}$. Ao $9^{\circ}$. anos $(11,6 \%), 24$ gestores escolares $(11,0 \%)$, 22 funcionários $(10,0 \%)$ e 23 Pais de alunos $(10,6 \%)$. Não foram consideradas as idades, tendo em vista a diversidade dos extratos. 


\section{Percepção dos alunos quanto a utilização do Programa de Tecnologias como estratégia didática}

Apresenta-se a seguir, as respostas dos alunos, quanto a suas percepções sobre alguns aspectos referentes a utilização do Programa de tecnologias como estratégia didática.

GRÁFICO 1 - Você já teve aulas no laboratório de informática da sua escola?

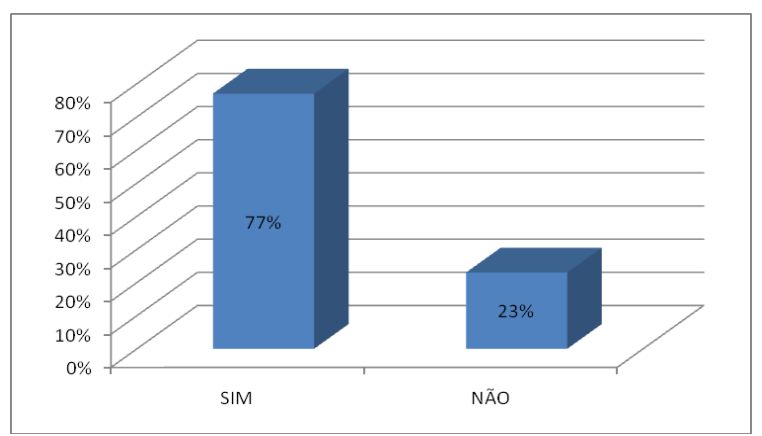

GRÁFICO 2 - O laboratório de informática de sua escola está conectado a rede de internet?

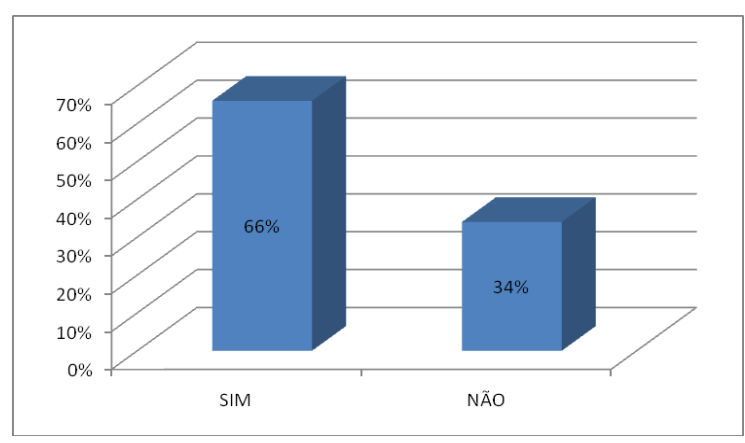

Segundo o Gráfico 2, 96 (77\%) alunos responderam que SIM e 28 (34\%) Responderam que NÃO. Portanto, apesar de não estar atingindo cem por cento dos alunos, parece estar havendo utilização dos laboratórios de informática na maioria das escolas.

Observando-se a questão envolvendo o gráfico 3, internet é um sistema mundial de redes de computadores interligadas, que utilizam um conjunto padrão de protocolos, de forma a servir simultaneamente a bilhões de usuários no mundo inteiro. Traz uma extensa possibilidade de recursos de informação e de serviços, tais como documentos, artigos, livros, e-mails para comunicação de apoio, dentre outros (GILDER, 1996).

Quanto a essa questão, 82 (66\%) alunos responderam que SIM e 42 (34\%) Responderam que NÃO. Embora a conexão com a rede global de computadores se apresente como uma ferramenta muito importante na educação, algumas escolas da zona rural, parecem estar apresentando este tipo de dificuldade, certamente por serem mais afastadas das torres de transmissão. 
GRÁFICO 3 - O laboratório de informática de sua escola está em funcionamento?

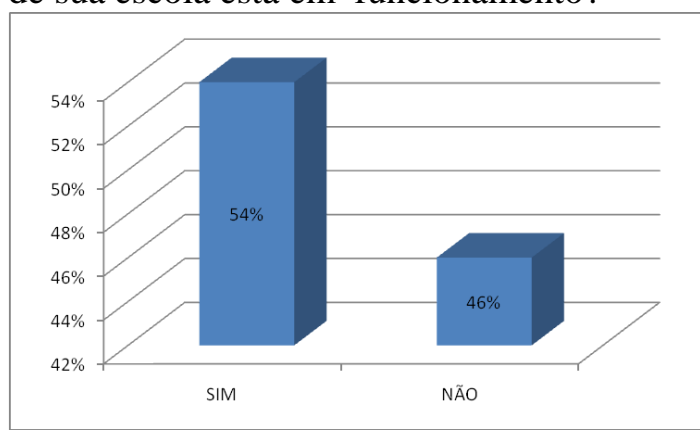

GRÁFICO 4 - Você gosta das aulas no laboratório de informática da sua escola?

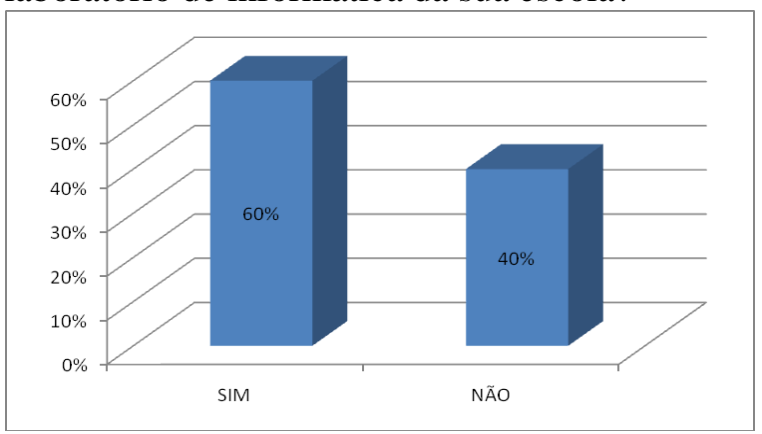

Relativamente a questão do gráfico 4, 67 (54\%) alunos responderam que SIM e 57 (46\%) Responderam que NÃO.

No caso da questão do gráfico 5, 75 (60\%) alunos responderam que SIM e 49 (40\%) Responderam que NÃO.

Discute-se as inúmeras possibilidades de interação, de pesquisa e de trocas à partir da internet, mas na prática, se uma escola não mantém como prioritário um projeto educacional com novas tecnologias didáticas, não irá modificar o processo já instalado. A Internet serve como uma ferramenta a mais, e isso precisa ser percebido como algo importante e motivador para o aluno, tanto do ponto de vista educacional como social. Caso contrário os alunos, eventualmente, ou alguns professores poderão estabelecer outras formas de comunicação menos avançadas e atuais, contrariando a filosofia proposta pelo programa Proinfo.

GRÁFICO 5 - A escola possui espaço físico adequado para o funcionamento do laboratório de informática?

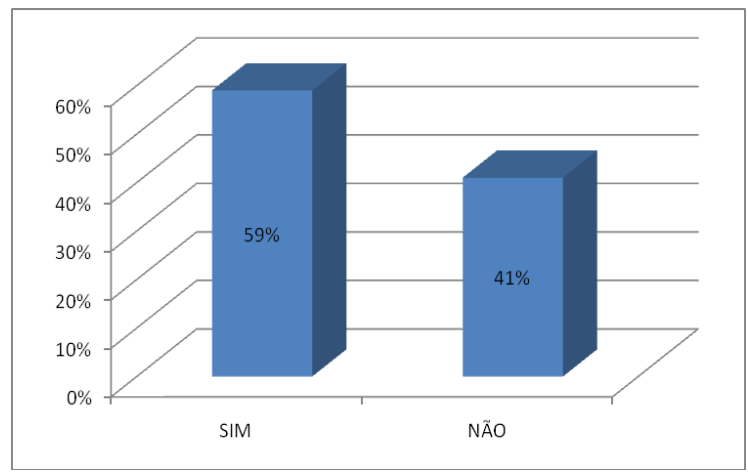

Os resultados demonstraram que, 73 (59\%) alunos responderam SIM e $51(41 \%)$

Responderam NÃO a adequação do espaço físico para um bom funcionamento do laboratório de informática na escola. 
O Ministério da educação no Brasil, juntamente com o Programa Nacional de Informática na Educação - ProInfo e Secretaria de Educação a Distância - SEED, instituíram em 2005, uma cartilha contendo uma série de recomendações para montagem de um laboratório de Informática nas escolas. O mesmo encontra-se disponível no seguinte endereço eletrônico: http://www.cted.educacao.rj. gov.br/nterj/escolas/me000353.pdf.

Dentre as recomendações encontram-se alguns pré-requisitos sobre a adequação do espaço físico e de instalações mínimas necessárias para se ter algum conforto e para se evitar problemas corriqueiros, a exemplo de: contemplar no mínimo 2 metros quadrados para cada computador instalado; protegido contra poeira, chuva, calor, e outros agentes que possam provocar desconforto aos usuários; Temperatura ambiente máxima de 30 graus; Tomadas elétricas sem compartilhamento entre mais de um aparelho; Ausência de falhas estruturais na alvenaria, hidráulica, mofo, infiltrações, etc; Piso adequado, sem desníveis ou batentes; Aterramento dos circuitos elétricos, dentre outros.

As respostas dos alunos evidenciam a percepção de algumas não conformidades em relação a adequação da infraestrutura oferecida pelas escolas no laboratório de informática.

GRÁFICO 6 - Quantas vezes, em média, você teve aulas no laboratório de informática?

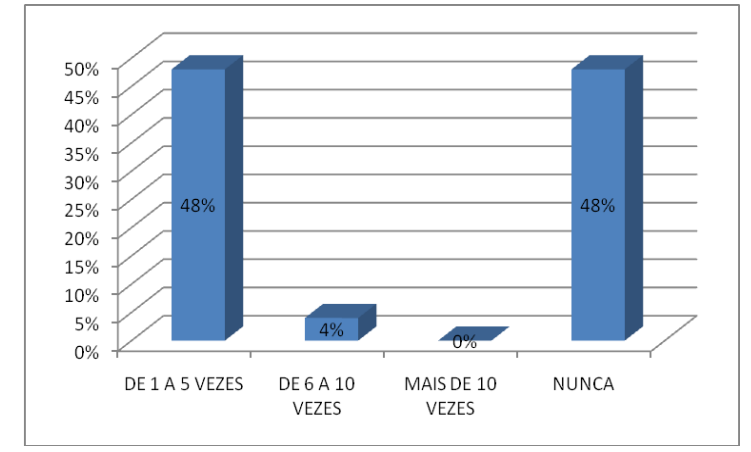

59 alunos responderam que de 1 a 5 vezes por mês; 6 alunos de 6 a 10 vezes por mês; nenhum aluno teve aula mais de dez vezes e, 59 alunos referiu que nunca assistiu aula no laboratório de informática.

A adequada utilização de aulas com uso de tecnologias, tende a proporcionar ao aluno uma maior motivação e interesse, implicando assim em melhorias no processo de ensino-aprendizagem. Portanto, ainda há que estimular nos professores, que os mesmos possam fazer uso de tais recursos com mais intensidade, já que há uma boa parcela dos alunos que referiram nunca terem aulas na sala de informática da sua escola.

Uma reflexão neste ponto é importante, pois para que as tecnologias educacionais possam ser utilizadas, precisam primeiro serem dominadas pelos professores. Estes devem se apropriar dos 
conhecimentos acerca dos recursos disponíveis, de forma que possam utilizá-los como instrumentos didáticos, diariamente nas suas aulas.

GRÁFICO 7 - Os professores usam a tecnologia nas aulas?

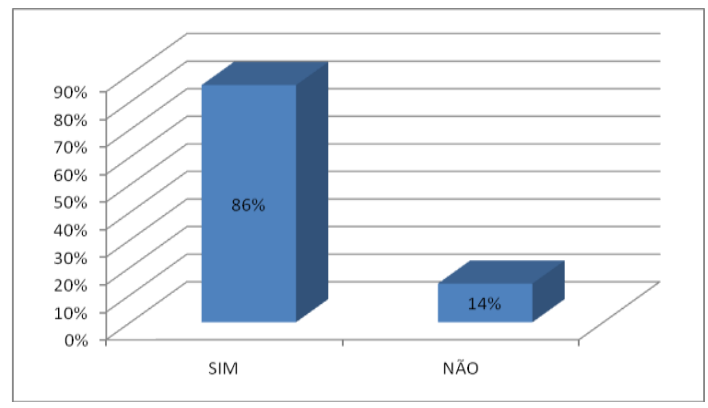

GRÁFICO 8 - Você acredita que o laboratório de informática da sua escola pode contribuir para aulas mais atraentes?

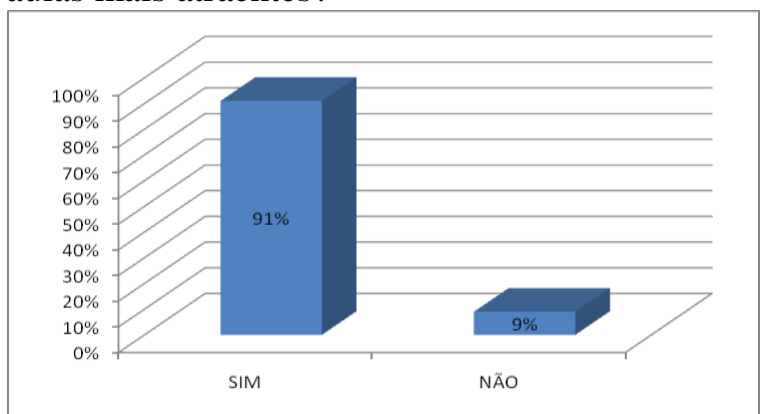

Quanto a questão do gráfico 8, 107 alunos responderam que SIM e 2 Responderam que NÃO.

Quanto a questão do gráfico 9,113 alunos responderam que SIM e 11 Responderam que NÃO.

As respostas as duas indagações anteriores, nos levam a crer que, os alunos parecem ávidos por aulas mais dinâmicas e atraentes (gráfico 9) e, que os professores parecem também menos intimidados em ofertar aulas com mais recursos (gráfico 8). A Nova LDB/96, incentiva todas as modalidades de ensino na utilização integrada de qualquer possibilidade de mídia eletrônica e impressa, que possibilitem uma melhoria na forma de transmissão do conhecimento. A internet, é uma forma qualitativamente interessante de integrar e/ou trazer a tona diversas possibilidades atrativas para as aulas: desde a própria TV, uso de textos escritos, figuras explicativas, pequenos documentários, músicas, teatro e vídeos .

A chegada da Internet nas escolas é portanto um marco decisivo em termos de abertura de possibilidades de aulas mais criativas e atraentes, capazes de envolver ativamente os alunos no seu fazer acadêmico.Trata-se portanto de um meio privilegiado de acesso à informação, que até bem pouco tempo eram impossíveis e/ou inimaginável.

GRÁFICO 9 - Em sua opinião a escola contribui para o acesso a tecnologia?

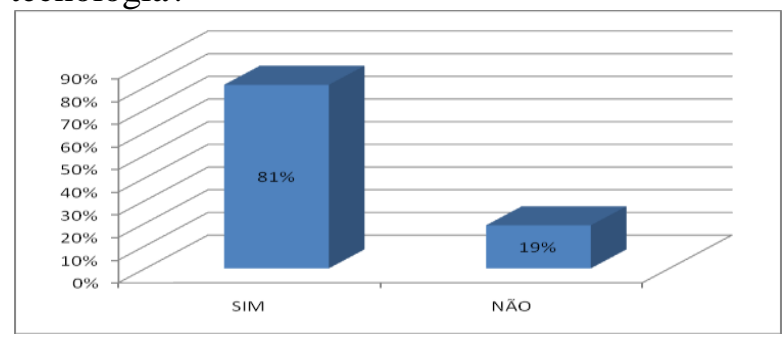


Quanto a esta questão, 100 alunos responderam que SIM e 24 Responderam que NÃO.

Diante das muitas transformações ocorridas no mundo e na história da humanidade, principalmente nos últimos anos, nos vemos em situações de mudanças constantes. Parece existir uma consciência de que, muitos dos paradigmas educacionais também foram sofrendo mudanças significativas por vivenciarmos uma era em que, as informações se processam muito rapidamente e, as comunicações tornaram-se essencial para compreensão e participação neste mundo globalizado.

Os avanços tecnológicos nos impelem para uma nova forma de ver o homem, como aquele que participa das suas práticas sociais, que é um sujeito ativo nos seus processos de aquisição dos conhecimentos.

Dessa forma, vislumbra-se uma escola que deixa de ser apenas transmissora de conteúdos e, volta-se à formação de um sujeito em seu sentido mais amplo.

A escola passa a condição de um espaço comprometido com a humanização. Neste sentido concordamos com Vasconcellos (2003) quando opina que a perspectiva da humanização precisa estar presente em cada instante da vida do indivíduo, uma vez que este se constitui e, se reorganiza ao transformar. É nesse sentido que se busca uma escola viva, dinâmica, democrática e vibrante; uma escola que olhe para o sujeito como uma totalidade, que o valorize e respeite em todas as suas dimensões, sejam elas emocionais, espirituais ou cognitivas. Uma escola que tenha uma contribuição para uma sociedade cada vez melhor.

Vasconcelos (2003) comenta neste sentido que, é preciso adicionar as grandes experiências humanas de amor, de liberdade, de felicidade, e de tecnologia, etc. a experiência do conhecimento. O autor acrescenta que, na medida em que o professor ajuda e estimula o aluno a ter acesso à cultura, a refletir criticamente a sua realidade, a imaginar, a criar, a atribuir valor, tende a desenvolver uma consciência, um sentido num contexto histórico, que é também coletivo.

GRÁFICO 10 - Em sua opinião, o fato de utilizar a tecnologia para o estudo, trouxe alguma melhora na sua aprendizagem.

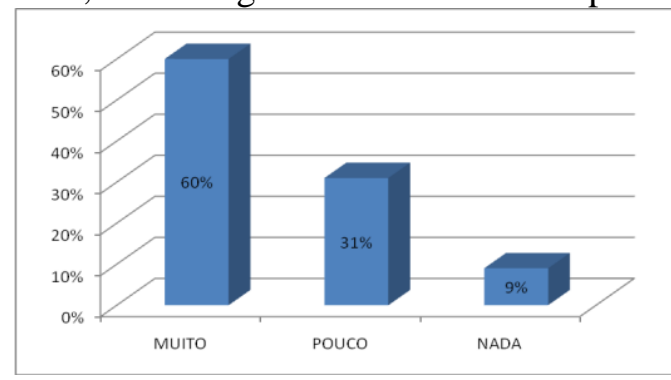

Com relação a esta indagação, 74 alunos responderam que MUITO, 39 responderam que POUCO e, 11 alunos responderam que em NADA o uso de novas tecnologias em sala de aula, melhorou sua aprendizagem.

21 Id en line Revista de Psicologia. Ano 9, No. 25, Fevereiro/2015 - ISSN 1981-1179. Edição eletrônica em http://idonline.emnuvens.com.br/id 
Observe-se que na percepção dos próprios alunos houve uma melhoria no processo ensino aprendizagem, já que em $60 \%$ dos casos, esta melhora foi percebida como muito significativa.

Neste sentido, Vigotski (2003, p.77) nos orienta que, a "educação é realizada através da própria experiência do aluno, que é totalmente determinada pelo ambiente em que está inserido; E neste caso, a função do professor se reduz à organização e à regulação de tal ambiente". Há nesta colocação a indicação de que o professor deveria buscar o fazer pensar, além de propiciar uma reflexão crítica e coletiva em sala de aula. Uma verdadeira atividade que, quanto mais interativa seja, possibilitaria processos mentais superiores. No pensamento de Vigotski (1987) é essencial que a intervenção do professor seja desafiante. Esta não pode estar muito abaixo do desenvolvimento real do aluno, ou muito acima do seu nível de desenvolvimento potencial. Há que haver um certo esforço para poder motivá-lo a atingir a zona de desenvolvimento proximal.

Dessa forma, caberia ao professor uma ação consciente de suas funções em sala de aula. Tal tomada de consciência impulsionaria a uma melhor organização e planejamento do seu trabalho pedagógico. Portanto buscar de forma mais consciente, desenvolver no educando suas várias habilidades e capacidades. Um educador mais provocativo, mais contagiante, capaz de despertar o desejo de realização por meio da interação educativa (VASCONCELLOS, 2003). Dessa forma, o professor agiria muito mais como um facilitador das relações, e um problematizador das situações sociais e cognitivas.

Em resumo, ensinar com novas tecnologias educacionais e, com a Internet atinge resultados significativos, mas somente quando se está integrado e imbuído num contexto estrutural de mudança real do processo de ensino-aprendizagem. Isso significa que professores e alunos precisam estar inseridos ativamente, vivenciando formas de comunicação modernas e abertas, de participação interpessoal e também grupal, efetivas. Se não for assim, os alunos não se perceberão importantes, contemplados, nem parte deste projeto. Dessa forma, a Internet será apenas uma tecnologia a mais, que irá reforçar as formas tradicionais de ensino. As novas tecnologias educacionais, nem a Internet, por si só, modificam o processo de ensinar e de aprender. É preciso também uma atitude gerencial e institucional, capaz de processar tal mudança.

\section{Percepção dos pais de alunos quanto a utilização das novas tecnologias de informação disponíveis na escola}

Apresenta-se a seguir, as respostas dos pais dos alunos, quanto às suas percepções sobre as novas tecnologias de informação disponíveis na escola. 
Gráfico 11 - Você conhece o laboratório de informática da escola do seu filho?

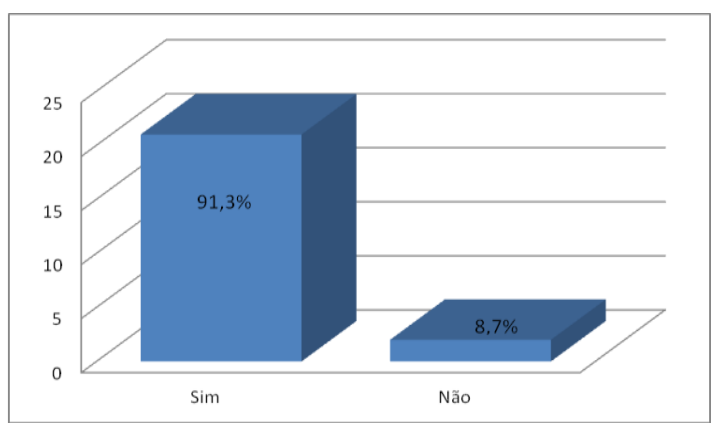

Gráfico 12 - A escola do seu filho dispõe de um espaço físico adequado para a instalação do laboratório de informática?

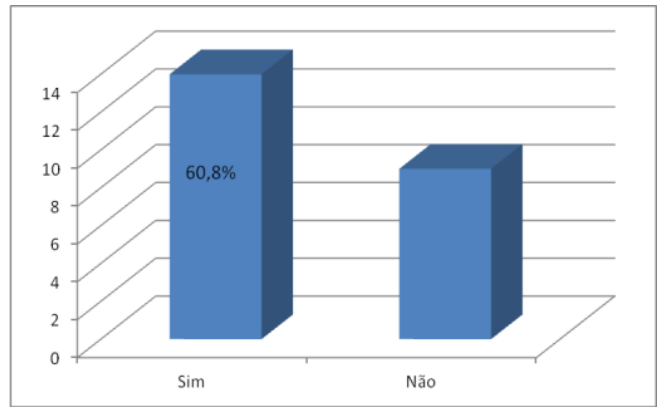

Quanto ao gráfico 11, 21 pais responderam que SIM e 2 Responderam que NÃO. Quanto ao gráfico 12, 14 pais responderam que SIM e 9 Responderam que NÃO.

GRÁFICO 13- O laboratório de informática da escola está em funcionamento?

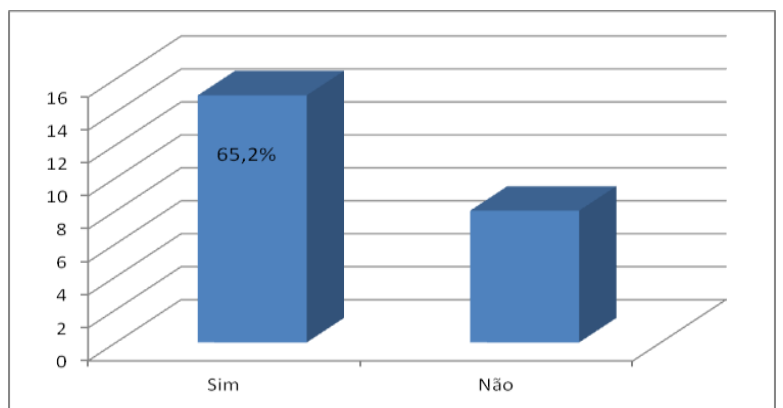

GRÁFICO 14 - Em sua opinião a escola contribui para o acesso a tecnologia?

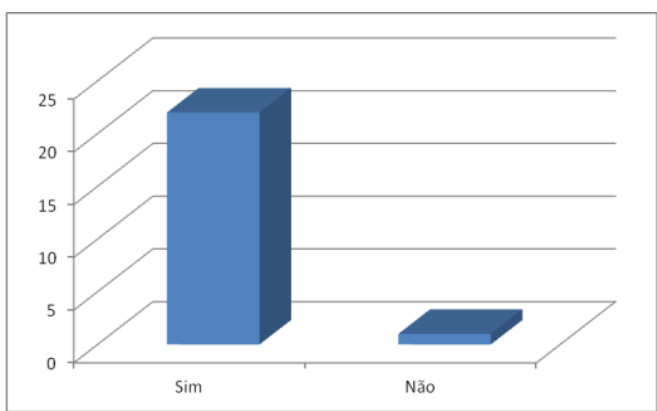

Com relação ao gráfico 13, sobre essa questão, 15 pais responderam que SIM e 8 Responderam que NÃO. Ao serem indagados sobre se acreditam que o laboratório de informática da escola pode contribuir para aulas mais atraentes, todos os 23 pais da amostra responderam que SIM.

Quanto ao gráfico 14, 22 pais responderam que SIM $(95,6 \%)$ e 1 Respondeu que NÃO $(4,4 \%)$.

As respostas dos pais é perfeitamente compreensível, tendo em vista ser a Internet é uma ferramenta fantástica na busca de caminhos novos, para proporcionar uma abertura para o novo, para o mundo das possibilidades. Porém, tais possibilidades só poderão se concretizarem, se, na prática, os profissionais também a utilizem, se esses também estiverem motivados para tal através de treinamentos que possibilitem tal habilidade e conhecimento. 


\section{Percepção dos funcionários quanto a utilização das novas tecnologias de informação disponíveis na escola}

Apresenta-se a seguir, as respostas dos funcionários, quanto às suas percepções sobre as novas tecnologias de informação disponíveis na escola.

GRÁFICO 15 - Você conhece o laboratório de informática da escola em que trabalha?

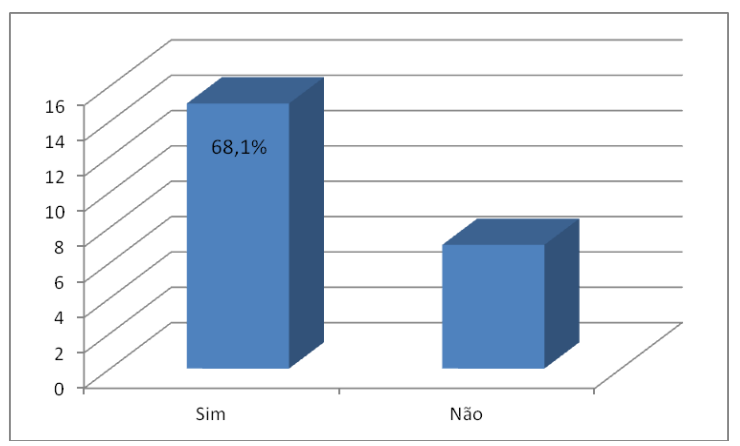

GRÁFICO 16 - Você acredita que a escola em que trabalha dispõe de um espaço físico adequado a instalação de um laboratório de informatica?

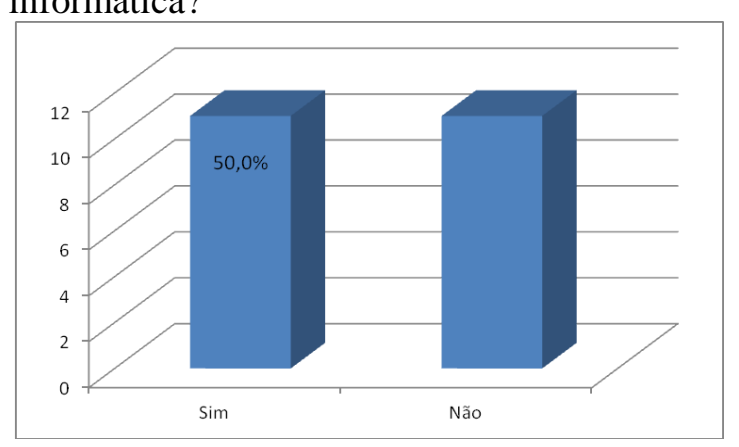

Sobre a indagação do gráfico 15, 15 funcionários $(68,1 \%)$ responderam que SIM e 7 responderam que NÃO (31,8\%). Conhecer sobre os recursos disponíveis na escola, em termos de novas tecnologias, é o primeiro passo para sua utilização. Também é uma aproximação importante para que os alunos percebam essa interatividade entre todos os níveis sociais da escola, na utilização da tecnologia disponível.

Quanto a questão do gráfico 16, neste item, 11 funcionários (50\%) responderam que SIM, que acreditam ser o espaço físico adequado, porém 11 (50\%) responderam que NÃO, que há que ter uma melhor infraestrutura mínima.

GRÁFICO 17 - O laboratório de informática da escola está em funcionamento?

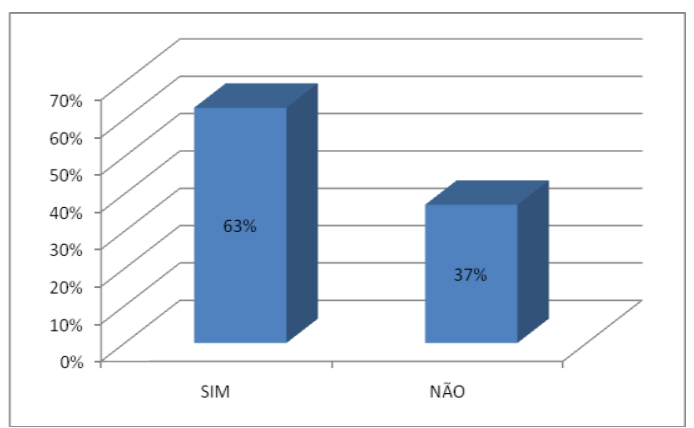

GRÁFICO 18 - Em sua opinião, a escola contribui para o acesso a tecnologia?

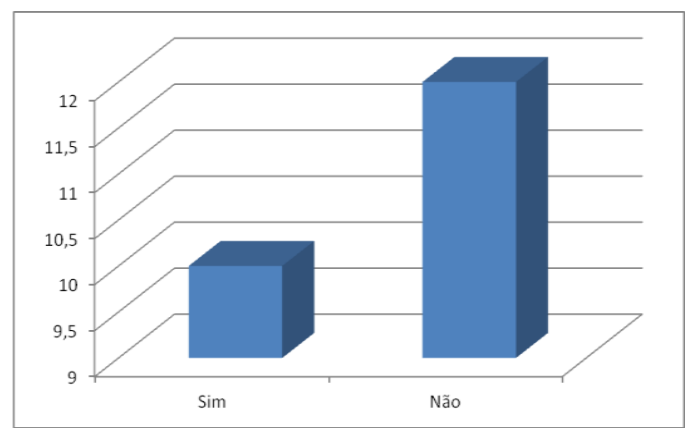


Quanto a questão do gráfico 17, 15 funcionários responderam que SIM e 7 Responderam que NÃO. Sobre o gráfico 18, 10 funcionários responderam que SIM (45,5\%) e 12 Responderam que NÃO $(54,5 \%)$.

Quando solicitados a responder sobre se observam o uso do laboratório de informática da escola pelos alunos, 10 funcionários ( 45,5\%) responderam que SIM e, 12 funcionários (54,5\%) responderam que NÃO.

Adicionalmente foi perguntado, se os funcionários acreditam que o laboratório de informática da escola pode contribuir para aulas mais atraentes. As respostas foram unanimemente que SIM $(100,0 \%)$.

\section{Percepção dos Gestores e Professores quanto a utilização do Programa de Tecnologias como estratégia didática}

A seguir, as respostas dos Gestores e Professores, quanto às suas percepções sobre as novas tecnologias de informação disponíveis na escola, utilizadas como recurso didático.

TABELA 2 - Percepção dos Gestores e Professores quanto a utilização do Programa de Tecnologias como estratégia didática

1) A quantidade de computadores é suficiente para o professor usar o laboratório de informática como ferramenta pedagógica?

\begin{tabular}{|l|c|c|c|c|}
\hline \multicolumn{1}{c|}{} & \multicolumn{2}{|c|}{ SIM } & \multicolumn{2}{c|}{ NÃO } \\
\cline { 2 - 5 } \multicolumn{1}{c|}{} & F & $\%$ & F & $\%$ \\
\hline Professores & 2 & 4,16 & 23 & 95,8 \\
\hline Gestores & 11 & 45,8 & 13 & 54,2 \\
\hline
\end{tabular}

2) Sua escola dispõe de um espaço físico adequado para a instalação do laboratório de informática?

\begin{tabular}{|l|c|c|c|c|}
\hline \multicolumn{1}{c|}{} & \multicolumn{2}{|c|}{ SIM } & \multicolumn{2}{c|}{ NÃO } \\
\cline { 2 - 5 } \multicolumn{1}{c|}{} & F & $\%$ & F & $\%$ \\
\hline Professores & 20 & 80,0 & 6 & 20,0 \\
\hline Gestores & 16 & 66,7 & 8 & 33,3 \\
\hline
\end{tabular}

3) O laboratório de informática de sua escola está em funcionamento?

\begin{tabular}{|l|c|c|c|c|}
\hline \multirow{1}{*}{\multicolumn{1}{c|}{}} & \multicolumn{2}{c|}{ SIM } & \multicolumn{2}{c|}{ NÃO } \\
\cline { 2 - 5 } \multicolumn{1}{c|}{} & $\mathrm{F}$ & $\%$ & $\mathrm{~F}$ & $\%$ \\
\hline Professores & 19 & 76,0 & 7 & 24,0 \\
\hline Gestores & 14 & 58,3 & 10 & 41,7 \\
\hline
\end{tabular}

4) A escola ou SME já ofereceu algum curso de formação na área de informática, com enfoque em metodologia?

\begin{tabular}{|l|c|c|c|c|}
\hline \multicolumn{1}{c|}{} & \multicolumn{2}{c|}{ SIM } & \multicolumn{2}{c|}{ NÃO } \\
\cline { 2 - 5 } \multicolumn{1}{c|}{} & F & $\%$ & F & $\%$ \\
\hline Professores & 6 & 24,0 & 20 & 76,0 \\
\hline Gestores & 5 & 20,8 & 19 & 79,2 \\
\hline
\end{tabular}

Continua... 
5) Quantas vezes em média os professores utilizam o laboratório de informática da escola como ferramenta pedagógica?

\begin{tabular}{|l|c|c|c|c|c|c|c|c|}
\hline \multicolumn{1}{c|}{} & \multicolumn{2}{|c|}{1 a 5 ao mês } & \multicolumn{2}{c|}{6 a 10 ao mês } & \multicolumn{2}{c|}{$\begin{array}{c}\text { Mais de } 10 \text { ao } \\
\text { mês }\end{array}$} & \multicolumn{2}{c|}{ Nunca utilize } \\
\cline { 2 - 10 } \multicolumn{1}{c|}{} & f & $\%$ & f & $\%$ & & & & \\
\hline Professores & 20 & 80,0 & - & - & - & - & 6 & 20,0 \\
\hline Gestores & 17 & 70,8 & - & - & 2 & 8,3 & 5 & 20,9 \\
\hline
\end{tabular}

6) Você acredita que o laboratório de informática da sua escola pode contribuir para aulas mais atraentes?

\begin{tabular}{|l|c|c|c|c|}
\hline \multirow{1}{*}{} & \multicolumn{2}{c|}{ SIM } & \multicolumn{2}{c|}{ NÃO } \\
\cline { 2 - 5 } \multicolumn{1}{c|}{} & F & $\%$ & F & $\%$ \\
\hline Professores & 25 & 100 & - & - \\
\hline Gestores & 24 & 100 & - & - \\
\hline
\end{tabular}

7) Em sua opinião a escola contribui para o acesso a tecnologia?

\begin{tabular}{|l|c|c|c|c|}
\hline \multicolumn{1}{c|}{} & \multicolumn{2}{c|}{ SIM } & \multicolumn{2}{c|}{ NÃO } \\
\cline { 2 - 5 } \multicolumn{1}{c|}{} & $\mathrm{F}$ & $\%$ & $\mathrm{~F}$ & $\%$ \\
\hline Professores & 19 & 76,0 & 6 & 24,0 \\
\hline Gestores & 24 & 100 & - & - \\
\hline
\end{tabular}

8) A escola tem tomado medidas para estimular o uso do laboratório de informática?

\begin{tabular}{|l|c|c|c|c|}
\hline \multicolumn{1}{c|}{} & \multicolumn{2}{c|}{ SIM } & \multicolumn{2}{c|}{ NÃO } \\
\cline { 2 - 5 } \multicolumn{1}{c|}{} & $\mathrm{F}$ & $\%$ & $\mathrm{~F}$ & $\%$ \\
\hline Professores & 18 & 72,0 & 7 & 28,0 \\
\hline Gestores & 14 & 58,3 & 10 & 41,7 \\
\hline
\end{tabular}

9) Você está satisfeito com o uso do laboratório de informática da sua escola como ferramenta pedagógica?

\begin{tabular}{|l|c|c|c|c|}
\hline \multicolumn{1}{c|}{} & \multicolumn{2}{c|}{ SIM } & \multicolumn{2}{c|}{ NÃO } \\
\cline { 2 - 5 } \multicolumn{1}{c|}{} & F & $\%$ & F & $\%$ \\
\hline Professores & 6 & 24,0 & 19 & 76,0 \\
\hline Gestores & 6 & 25,0 & 18 & 75,0 \\
\hline
\end{tabular}

10) Em sua opinião, o fato de utilizar a tecnologia para o estudo, trouxe alguma melhora na aprendizagem dos alunos?

\begin{tabular}{|l|c|c|c|c|c|c|}
\multicolumn{1}{c|}{} & \multicolumn{2}{c|}{ MUITO } & \multicolumn{2}{c|}{ POUCO } & \multicolumn{2}{c|}{ NADA } \\
\cline { 2 - 7 } \multicolumn{1}{c|}{} & $\mathrm{F}$ & $\%$ & $\mathrm{f}$ & $\%$ & $\mathrm{f}$ & $\%$ \\
\hline Professores & 10 & 40,0 & 13 & 52,0 & 2 & 8,0 \\
\hline Gestores & 2 & 8,4 & 12 & 50,0 & 10 & 41,6 \\
\hline
\end{tabular}

11) Você percebe interesse dos alunos em usar o laboratório de informática?

\begin{tabular}{|l|c|c|c|c|c|c|}
\hline \multicolumn{1}{c|}{} & \multicolumn{2}{c|}{ MUITO } & \multicolumn{2}{c|}{ POUCO } & \multicolumn{2}{c|}{ NADA } \\
\cline { 2 - 7 } \multicolumn{1}{c|}{} & F & $\%$ & F & $\%$ & f & $\%$ \\
\hline Professores & 16 & 64,0 & 7 & 28,0 & 2 & 8,0 \\
\hline Gestores & 13 & 54,2 & 11 & 45,8 & - & - \\
\hline
\end{tabular}

Fonte: Pesquisa própria

Com relação a tabela 2, algumas questões foram percebidas por professores e gestores de forma menos positiva. Foram elas:

a) A questão 1 , sobre se a quantidade de computadores é suficiente para o professor usar o laboratório de informática como ferramenta pedagógica, ao que $95,8 \%$ dos professores e $54,2 \%$ dos gestores afirmaram que NÃO é suficiente. 
A falta de recursos materiais tende a desestimular o uso da sala de informática, causando uma série de prejuízos aos alunos e professores. Desde as dificuldades de se levar a cabo aulas mais dinâmicas e atraentes até a possibilidade de desacordos e desentendimentos relacionais entre os alunos, por conta do compartilhamento de aparelhos que estejam funcionando adequadamente, etc.

No caso de Banabuiú, essa percepção negativa atingiu 92\% dos professores, que insistem em que as salas necessitam de um maior aparato em termos de recursos materiais, para que possam desenvolver seu trabalho adequadamente.

b) A questão 4, sobre se a escola ou a Secretaria Municipal de Educação já ofereceu algum curso de formação na área de informática, com enfoque em metodologia, ao que ao que $76 \%$ dos professores e 79,2\% dos gestores afirmaram que NÃO. Que não foi oferecido aos professores cursos ou treinamentos específicos para que possam utilizar o laboratório de informática.

Um outro ponto percebido como negativo pelos professores e gestores foi quanto a falta de treinamento específico para os mesmos sobre as novas tecnologias e seu uso didático.

$\mathrm{O}$ avanço tecnológico e suas conseqüências vem trazendo para a sociedade e para a escola; um aumento em torno das discussões sobre a formação de professores no domínio e incorporação das novas tecnologias na escola e na prática docente. A idéia é proporcionar um desenvolvimento profissional adequado às novas demandas.

Em meados de 80, época em que a tecnologia da informática começou a ser nvestigada no sistema educacional brasileiro (ALMEIDA, 1987), observou-se a importância e necessidade de uma capacitação dos professores para o uso da informática na educação de forma a trazer contribuições ao processo ensino- aprendizagem. Alguns projetos como o EDUCOM, de 1984, e mais recentemente o PROINFO Programa Nacional de Informática na Educação), criado em 1997, já trouxeram essa filosofia em seu eixo norteador.

Em relação aos aspectos teóricos e metodológicos que os professores precisam aprender a fazer uso no planejamento e execução de suas atividades, percebeu-se uma maior preocupação dos mesmos em termos do domínio da máquina e dos softwares associados. Portanto a necessidade parece ser básica em relação a tal questionamento.

O domínio requer prática e saberes associados a essa prática, portanto estratégias que envolvam mais os professores e no uso desta nova ferramenta parecem de grande relevância para o sucesso do Proinfo em banabuiú.

Em relação aos saberes e conhecimentos imprescindíveis para a tarefa educativa, esses saberes devem já estar atrelados aos objetivos que se pretende alcançar e com a realidade dos implicados neste processo. A informática como toda nova tecnologia, tem caráter mutante contínuo. Isso é, estão sempre se modificando, se aperfeiçoando, portanto a capacitação precisa ser contínua para ser realmente eficaz. 
O presente estudo constatou através da percepção dos professores e gestores uma carência nesta área. Além disso, parece haver uma certa indefinição quanto aos saberes a serem mobilizados para uma prática docente envolvendo tecnologias.

c) A questão 9 sobre se o professor está satisfeito com o uso do laboratório de informática da sua escola como ferramenta pedagógica, ao que $76 \%$ dos professores e $75 \%$ dos gestores afirmaram que NÃO estão satisfeitos com o uso do laboratório de informática como ferramenta pedagógica.

Essa questão parece ser uma consequência das questões anteriores. Se não se tem os recursos adequados nem o treinamento suficiente ao domínio de certas habilidades e conhecimentos necessários a implementação da tarefa, esta realmente fica prejudicada. Portanto as percepções dos professores encontram-se em sintonia com a situação constatada.

Autores como Minicucci (2001), afirmam que é através do trabalho que o indivíduo alcança a satisfação de muitas de suas necessidades. O presente estudo observou que poucos são os que realmente satisfeitos com o laboratório de informáticas das escolas em que atuam e, consequentemente com o trabalho que lá desempenham. White (1992, p. 14), nos orienta que, "os conflitos pessoais, trabalho e ambição excessiva, pressões financeiras, receio de desemprego, tédio, falta de oportunidade e incontáveis outros problemas atormentam sua existência".

A satisfação laboral também é definida por Oliveira (2009, p.196) como um conjunto de sentimentos, quer favoráveis ou desfavoráveis, que acometem os empregados quando pensam em seu trabalho. A Satisfação para com o trabalho pode referir-se apenas às atitudes de um único professor, bem como acometer a maioria dos componentes de determinado grupo (OLIVEIRA, 2009). No presente estudo, acomete $76 \%$ dos professores e $75 \%$ dos gestores das escolas da amostra.

No campo da Educação, Bastos (PEIXOTO, 2006) defende que a satisfação no trabalho reflete uma percepção, cheia de componentes afetivos, associada a aspectos como envolvimento no trabalho, autoestima, e comprometimento organizacional.

A satisfação no trabalho, é também uma parcela da satisfação com a vida, e tende a influenciar outras áreas na vida dos indivíduos, a exemplo da autoconfiança, das atitudes em relação à família e aos amigos, dentre outras. Também deve-se avaliar uma relação da satisfação com o trabalho e a saúde, física e/ou psíquica (OLIVEIRA, 2009).

Com relação a este último aspecto, Chopra (1991, p. 134), orienta que "as pessoas vivem melhor se estiverem satisfeitas no trabalho". Segundo o autor, quando as pessoas não gostam do que fazem, ou não estão satisfeitas com seu trabalho, apresentam uma tendência ao desenvolvimento de sintomas como dores de cabeça, inapetência, insônia, obesidade, ansiedade, hipertensão, problemas cardíacos, dentre outro.

Portanto, o atendimento a essa demanda dos professores é de extrema importância, tanto para o ensino-aprendizagem dos alunos, como para a própria saúde física e mental dos professores. 
Por outro lado, muitos foram também os aspectos percebidos como positivos, tais como a adequação do espaço físico do laboratório de informática e seu funcionamento; O número de vezes em que tem sido utilizado; a crença de que o laboratório de informática da sua escola pode contribuir para aulas mais atraentes e que a escola contribui para o acesso a tecnologia; E que além disso, a escola tem tomado medidas para estimular o uso do laboratório de informática e que os próprios alunos demonstram o interesse em usar esta ferramenta de apoio.

Ao que parece, a própria Secretaria Municipal de Educação tem se empenhado no provimento de recursos materiais aos laboratórios de informática nas instituições educacionais. Observe-se um levantamento sobre a distribuição de equipamentos do Proinfo nas escolas de 2008 a 2013, na tabela 3 a seguir:

TABELA 3: Distribuição de Computadores do Proinfo para as Escolas Públicas Municipais/ 2008-2013. Banabuiú, 2014.

\begin{tabular}{c|c|c|c|c}
\hline ANO & F & Fr & F & Fr \\
\hline 2008 & 10 & $7 \%$ & 10 & $7 \%$ \\
\hline 2009 & 30 & $21 \%$ & 40 & $28 \%$ \\
\hline 2010 & 50 & $35 \%$ & 90 & $63 \%$ \\
\hline 2011 & 36 & $25 \%$ & 126 & $88 \%$ \\
\hline 2012 & 18 & $12 \%$ & 144 & $100 \%$ \\
\hline 2013 & 0 & $0 \%$ & 144 & $100 \%$ \\
\hline TOTAL & $\mathbf{1 4 4}$ & $\mathbf{1 0 0 \%}$ & - & - \\
\hline
\end{tabular}

Fonte: Secretaria Municipal de Educação de Banabuiú

Os resultados demonstram uma certa regularidade a cada ano, na distribuição de computadores e assessórios associados diretamente às escolas públicas municipais, participantes do Programa proinfo.

Na sequência, os resultados em termos de aprendizagem de 2009 a 2013, demonstrando assim que há uma associação diretamente proporcional entre o investimento em recursos materiais e um salto positivo em termos de aprendizagem dos alunos.

TABELA 4: Resultado da Aprendizagem das Escolas Públicas Municipais segundo o Sistema Municipal de Avaliação /2008-2013. Banabuiú, 2014.

\begin{tabular}{c|c|c|c|c|c}
\hline NíVEL & $\mathbf{2 0 0 9}$ & $\mathbf{2 0 1 0}$ & $\mathbf{2 0 1 1}$ & $\mathbf{2 0 1 2}$ & $\mathbf{2 0 1 3}$ \\
\hline $1^{\circ}$ ao $5^{\circ}$ & 88 & 79 & 76 & 79 & 85 \\
\hline $6^{\circ}$ ao $9^{\circ}$ & 51 & 47 & 38 & 46 & 46 \\
\hline $\mathbf{1}^{\circ}$ ao $9^{\circ}$ & $\mathbf{7 0}$ & $\mathbf{6 3}$ & $\mathbf{5 7}$ & $\mathbf{6 3}$ & $\mathbf{6 6}$ \\
\hline
\end{tabular}

Fonte: Secretaria Municipal de Educação de Banabuiú 
Para uma melhor visualização observe-se o gráfico 20 , que demonstra a distribuição de computadores nas escolas públicas de Banabuiú de 2008 a 2013 versus a aprendizagem alcançada pelos alunos no mesmo período.

GRÁFICO 19 - Distribuição de computadores nas escolas públicas de Banabuiú x Aprendizagem alcançada pelos alunos entre 2008 a 2013. Banabuiú, 2014.

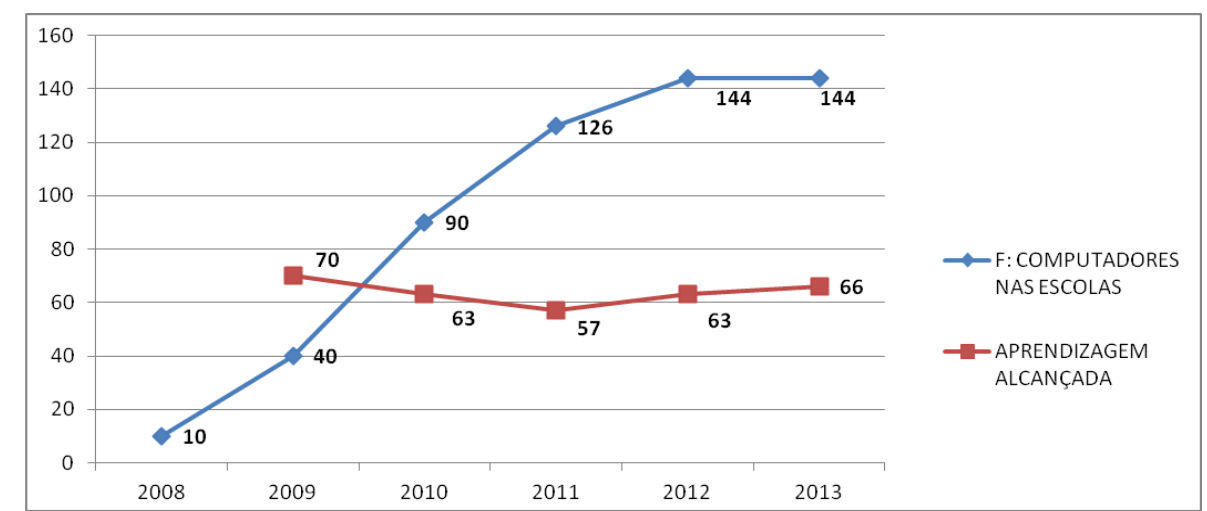

Fonte: Secretaria Municipal de Educação de Banabuiú

O Gráfico 19 demonstra um crescimento da aprendizagem alcançada pelos alunos associado a distribuição de computadores nas escolas.

Esta aprendizagem poderia acompanhar mais proximamente o gráfico da distribuição de computadores, mas tendo em vista alguns fatores a falta de capacitação intensiva dos professores na área da informática, a infra-estrutura nem sempre adequada dos laboratórios, dentre outros fatores negativos na implantação do projeto Proinfo, isso não parece acontecer na mesma intensidade.

A partir dos resultados, percebeU-se que os professores e gestores são bastante otimistas e que estão sempre em busca de novos meios que facilitem e favoreçam o desenvolvimento educacional dos alunos. Em muitos casos vezes sem medir esforços, sedentos por novidades em termos didáticos. Desta forma, as novas tecnologias educacionais, facilitadas pela informática e internet, não passarão despercebida pelas escolas. Afinal, é o educador que realmente fará a diferença.

Detectamos também, que as suas angústias e questionamentos, parecem relacionados justamente com a sua percepção da educação, desejosos de uma melhoria que possa amenizar seus problemas. Nem sempre conseguindo, mas sempre tentando fazer o seu melhor.

Em resumo, ensinar com o aparato da internet representa uma verdadeira revolução em termos educacionais, mas é preciso mudarmos também os paradigmas do ensino. Caso contrário, esta servirá somente como um paliativo, uma espécie de jogada de marketing para mascarar o ensino como mais moderno e atual, quando na verdade todo o processo estaria comprometido. 
Se todas as etapas previstas não são cumpridas a contento, principalmente em termos de preparação dos educadores, é mais provável que não se tenha êxito com o Projeto.

Educar requer investimento e, nesta profissão a capacitação é fundamental para se compreender o processo para um melhor agir, ou melhor, um agir consciente da responsabilidade que cabe a cada um.

\section{Considerações Finais}

O presente estudo teve o objetivo de discutir aspectos referentes às contribuições na utilização do Programa Nacional de Tecnologia Educacional - Proinfo, nas escolas públicas municipais de Banabuiú, estado do Ceará - Brasil.

Sempre que se propõe uma iniciativa arrojada como é este programa, (Proinfo) uma série de políticas públicas voltadas para a educação, precisam ser associadas a este, de maneira que se possa atingir os objetivos pedagógicos propostos inicialmente.

O objetivo principal do Proinfo é o de promover o uso pedagógico das novas tecnologias de informática na rede pública de educação básica, dotando as escolas de computadores, de recursos digitais e de conteúdos educacionais associados. Em contrapartida, os estados e municípios se comprometem a garantir uma infraestrutura adequada para as instalações dos laboratórios, bem como a capacitação dos educadores, para operacionalização na prática.

Trata-se de uma iniciativa política da maior importância, visto que mundialmente as pessoas estão cada vez mais conectadas e utilizando uma forma de comunicação jamais imaginada. O ProInfo é um programa proposto pelo MEC visando um ajustamento e universalização, no uso de tecnologias no sistema público de ensino. Esta estratégia faz parte de um conjunto de ações, voltadas para o aperfeiçoamento e modernização da ação pedagógica na sala de aula e, por que não dizer, na gestão da escola.

A base ideológica é a promoção da qualidade do ensino público brasileiro, tornando-o mais competitivo frente a uma sociedade cada vez mais informatizada.

Segundo documentos públicos oficiais, há recursos do Proinfo destinados a capacitação de recursos humanos, bem como a implantação de uma infra-estrutura mínima adequada às necessidades dos usuários e, para um suporte técnico que assegure o bom funcionamento dos equipamentos, no seu uso educacional.

Portanto, diante das percepções dos envolvidos, o programa ainda carece de alguns ajustes importantes, para que possa realmente atingir os objetivos almejados. 
Certamente que a iniciativa do Ministério da Educação e Cultura - MEC, na promoção do uso pedagógico dos recursos da informática na rede pública, é da mais alta importância para a população atendida. Porém, alguns aspectos essenciais, merecem ser realçados.

O primeiro evidencia uma evolução nas tecnologias didáticas e de comunicação, destacando uma necessidade social de uma adequação de estratégias didáticas associadas a contemporânea. $\mathrm{O}$ segundo aspecto diz respeito a implantação do Programa Nacional de Informática na Educação (PROINFO) no município de Banabuiú - CE, marcando uma nova fase em termos de trabalho didático entre os educadores municipais.

Com relação ao uso do computador como tecnologia educacional, observou-se que o mesmo ainda vem sendo utilizado apenas como instrumento auxiliar, pouco acrescentando à dinâmica do ensino. Mesmo sendo uma tecnologia avançada, os professores ainda não se mostraram preparados para tal investidura, até porque não estão sendo alvo da capacitação prevista no projeto.

O Proinfo, apesar de ter na sua concepção uma boa direção teórica para o desenvolvimento de suas etapas de atividades propostas, os resultados do presente estudo mostraram que a efetivação do Programa ainda carece de ajustes para seu pleno funcionamento.

A falta de manutenção dos equipamentos, bem como a carência de material de consumo, são outros aspectos que se mostraram desmotivadores, na percepção dos entrevistados, principalmente dos professores, no planejamento de aulas no laboratório de informática.

Apesar dos indicadores demonstrarem um rendimento melhor dos alunos quando comparados a oferta e distribuição de computadores nas escolas, este fato por si só não nos parece suficiente para tirar tais conclusões, tendo em vista uma série de outras dimensões associadas que não tem sido implementadas com o êxito esperado.

O presente estudo evidencia claramente a necessidade de uma proposta sincronizada entre as ações educativas, desde a inevitável formação específica para os professores, com treinamentos continuados e atualizações didáticas constantes, até a dotação de recursos financeiros para dar conta do material de consumo necessários a um bom funcionamento dos laboratórios de informática.

A relação escola-informática mostrou-se relativamente contraditória. Sua expressão ficou clara nas entrevistas, por exemplo, quanto a queixas dos professores sobre as dificuldades e falta de apoio dos gestores municipais e governos, geradores de conformismo e desânimo. As entrevistas revelam a contradição da relação escola-informática, também, nas falas e sentimentos dos entrevistados, que, pareceram sentir-se "à própria sorte" (grifo nosso), a despeito das demonstrações de falta de incentivo e apoio, para o seu fazer pedagógico.

Neste real contraditório, alguns autores que tratam sobre questões da escola pública, lutam para dar maior clareza e compreensão a organização didática nas escolas atualmente. 
Quanto a isso, dois estudos merecem destaque: Cella (2000) e Rosa (2000) que, embora tenham concentrado suas pesquisas em outras regiões do País, apresentam resultados parecidos, e que reforçam conclusões similares ao presente estudo. Percebe-se pois que, a implantação das novas tecnologias educacionais e a informática na educação em Banabuiú, ainda está um tanto distante do preconizado nos documentos oficiais, notadamente no Proinfo.

As escolas públicas, parecem ainda caminharem no sentido de preservar o tradicionalismo didático, mesmo quando impelidas a um movimento diferente, ditado pelos modismos educacionais. Estão ainda carecendo de uma consciência maior dos seus gestores federais, estaduais e municipais, que os envolva numa real proposta de trabalho, capaz de produzir as melhorias que o processo ensinoaprendizagem hoje demandam.

Sabe-se que o sucesso da educação não se concentra somente nas ferramentas metodológicas utilizadas, mas essencialmente na presença do professor. Este constantemente buscando meios para melhorar a qualidade do ensino, tem a sua disposição agora, a tecnologia da informática, onde seus recursos certamente irão possibilitar um novo caminho a ser percorrido.

Em resumo, percebeu-se que o ProInfo em Banabuiú é um investimento inovador e, que certamente trará contribuições muito significativas para a educação cearense.

\section{Recomendações}

No mundo inteiro, diversas instituições governamentais e grupos internacionalmente reconhecidos, tentam impulsionar uma melhoria na educação, atraindo estudiosos e acadêmicos de todas as partes do globo. Poucos, contudo, parecem verdadeiramente guiados por agendas que contemplem populações menos favorecidas. É possível que outras iniciativas educacionais como esta, possam diminuir a distância social em termos de conhecimento e consequentemente melhorem as oportunidades para esta parcela da população.

Pesquisas que envolvam outros municípios do Ceará serão interessante, pois podem fornecer informações para uma ideia mais contextualizada do andamento do Proinfo em termos de Estado. Outras recomendações vão no sentido de: a) Promover a inclusão de uma avaliação periódica sobre o uso do laboratório de informática em todas as escolas, para verificar a efetividade da implementação das sugestões propostas por este estudo; b) Estimular a criação de um Núcleo de Tecnologia Educacional - NTE para formação e estudo da tecnologia educativa, no município; c) Oferecer cursos de inclusão digital para a comunidade, em todas as instituições de ensino públicas de Banabuiú; d) Disponibilizar no NTE, um professor do município com formação em tecnologia educativa, para apoiar os usuários no laboratório; e) Oferecer condições para que o professor do NTE, possa 
acompanhar periodicamente todas as escolas do município; f) Apresentar e divulgar a concepção do ProInfo para toda comunidade escolar.

\section{Referências}

ALMEIDA, Maria Elizabeth Bianconcini . Informática e Formação de professores. 1. ed. Brasília: Ministério da Educação, 2000. v. 2. 191p .

O aprender e a Informática: a arte do possível na formação do professor. Brasília: Ministério da Educação, 1999. v. 1.39p .

ALMEIDA, Maria Elizabeth Bianconcini ; ALMEIDA, Fernando José de . Aprender construindo: a informática se transformando com os professores. Brasília: Secretaria de Educação a Distância, MEC, 1999. v. 1. s.n.p .

ALMEIDA, M.E.B.T.M.P. Informática e Educação - Diretrizes para uma Formação Reflexiva de Professores. Tese de Mestrado. São Paulo: Departamento de Supervisão e Currículo da PUC, 1996.

ALMEIDA, F. J. de. (Org.). Educação e Informática: os computadores na escola. Coleção Polêmicas do Nosso Tempo, vol. 19. São Paulo: Cortez: Autores Associados, 1987.

ANDRADE, P.F. e LIMA, M.C.M.A. Projeto EDUCOM. Brasília - DF: Ministério da Educação e Organização dos Estados Americanos, 1993.

ANDRADE, P.F. Projeto EDUCOM: Realizações e produtos. Brasília - DF: Ministério da Educação e Organização dos Estados Americanos, 1993.

AZEVEDO, W. Panorama da Educação a Distância no Brasil. Aquifolium. Disponível em < http://aquifolium.com.br/educacional/artigos/panoread.html > Acesso em 22/04/2014.

BALACHEFF, N. Contribution de la didactique et de l'epistémologie aux recherches en EIAO. In: BELLISANT, C. (Ed.). Actes des XIII Journées Francophones de l'informatique. Grenoble: IMAG-CNRS, 1991. p.181-215.

BELLEMAIN, F. Cabri-geomètre, um CAhier de BRouillon Informatisé pour la résolution de problèmes de géometrie plane. In: Document interne LSD2. Grenoble: IMAG, 1991. p.6189.

BOB Albrecht, et al. Atividades Computacionais na Prática Educativa de Ciências e Matemática - MEC 1. ed. Brasília: MEC/SEED/Proinfo, 1999.

BRASIL - Ministério da educação no Brasil; Secretaria de Educação a Distância - SEED; Programa Nacional de Informática na Educação - ProInfo. Cartilha: recomendações para montagem de um laboratório de Informática nas escolas. Brasília - DF, 2005. Disponível em < http://www.cted.educacao.rj.gov.br/nterj/escolas/me000353.pdf> Acesso em 11/11/2014.

CELLA, Carmen Rejane. A democratização do acesso à informática na educação: um estudo avaliativo do Proinfo-Programa Nacional de Informática Educativa. Florianópolis: Curso de PósGraduação em Engenharia de Produção/UFSC, 2000. 189 p. (Dissertação de mestrado) 
CHAVES, Eduardo Oscar de Campos . Tecnologia e Educação: O Futuro da Escola na Sociedade da Informação. Brasília: Ministério da Educação, 1999. v. 1.

CHOPRA, Deepak. Conexão saúde. Trad. Ibraíma da Fonte Tavares. São Paulo: Best Seller, 1991.

CLEMENTE, Fabiane apud GIL, A. C. (2007). Pesquisa qualitativa, exploratória e fenomenológica: Alguns conceitos básicos. Sítio Administradores $<$ http://www.administradores.com.br/informe-se/artigos/pesquisa-qualitativa-exploratoria-efenomenologica-alguns-conceitos-basicos/14316/>. Acessado em 17 de abril de 2014.

COLLIS, Jill; HUSSEY, Roger. Pesquisa em Administração (2 ed.). Porto Alegre: Bookman, 2005.

DIEHL, Astor Antonio. Pesquisa em ciências sociais aplicadas: métodos e técnicas. São Paulo: Prentice Hall, 2004

FAGUNDES, L. C. ; SATO, L. S. ; MAÇADA, D. L. . Aprendizes do Futuro : asinovações começaram. 1. ed. Brasília: PROINFO/SEED/MEC, 1999. v. 19. 95p.

FONSECA JUNIOR, F. M. ; ALMEIDA, F. J. . Aprendendo com Projetos - MEC. 1. ed. Brasília: MEC - SEED - ProInfo, 1999. v. 1. 44p .

FONSECA Junior, F. M. ; ALMEIDA, F. J. . Criando Ambiente Inovadores - MEC. 1. ed. Brasília: MEC - SEED - ProInfo, 1999. v. 1. 41p .

FREIRE, Paulo. Pedagogia da autonomia: saberes necessários à prática educativa. São Paulo: Paz e Terra, 1996.

GIL, Antônio Carlos. Métodos e técnicas de pesquisa social. São Paulo: Atlas, 1999.

GILDER, George. Vida após a televisão: vencendo na revolução digital. Rio de Janeiro, Ediouro, 1996.

INGERSOLL, R.I. Four myths about America's teacher quality problem. In: SMYLIE, M.A.; MIRETSKY, D. (Ed.). Developing the teacher workforce. Chicago: University of Chicago Press, 2004.

INGERSOLL, R.I. The problem of underqualified teachers in American secondary schools. Educational Researcher, n. 28, p. 26-37, 1999.

KENSKI, Vani Moreira. Educação e Tecnologias: O novo ritmo da informação - $8^{\mathrm{a}}$ Ed. Campinas, SP: Papirus, 2012. 141p.

LAKATOS, Eva Maria; MARCONI, Marina de Andrade. Fundamentos de metodologia científica. [S.1.]: Atlas, 2010, p. 28)

LEACH, J.; MOON, B. Globalisation, digital societies and school reform: realising the potential of new technologies to enhance the knowledge, understanding and dignity of teachers. 2nd European Conference on Information Technologies in Education and Citizenship: a critical insight. Barcelona, 2002. 
LÉVY, P. Les technologies de l'intelligence: l'avenir de la pensée à l'ère informatique. Paris: Éditions La Découverte, 1990. 235p.

LABORDE, C.; LABORDE, J. M. Micromondes intelligents et environement d'apprentissage. In: BELLISANT, C.(Ed.). Actes des XIII Journées Francophones de l'informatique. Grenoble, IMAG-CNRS, 1991. p.218-40.

MARCONI, Marina de Andrade; LAKATOS, Eva Maria. Técnicas de pesquisa. 5. ed. São Paulo: Atlas, 2002

MCLUHAN, Marshall. A galáxia de Gutenberg. 2 ed. São Paulo: Nacional, 1977. p. 54-60 e p. 340342

MINICICCI, Agostinho. Relações Humanas: Psicologia das Relações Interpessoais. 6 ed. São Paulo: Atlas, 2001.

MOON, B. The Open Learning Environment: a new paradigm for international developments in teacher education. In: MOON, B.; BEN PERETZ, M.; BROWN, S (Ed.). Routledge International Companion to Education. London: Routledge, 2000.

MOON, B.; LEACH, J.; STEVENS, M. Designing open and distance learning for teacher education in Sub-Saharan Africa: a toolkit for educators and planners. Washington, DC: The World Bank, 2005.

MORAN, José Manuel. Ensino e aprendizagem inovadora com tecnologias audiovisuais e telemáticas In: Moran, Maseto, Marcos Tarcisio, Behrens, Marilda A. Novas Tecnologias e Mediação.8 ed. Campinas: Papirus, 2004. p.11-63.

MORGADO, Eduardo Martins, et al. Preparação de Ambientes Informatizados nas Escolas Públicas - MEC 1. ed. Brasília: MEC/SEED/Proinfo, 1999.

OLIVEIRA, Silvio Luiz. Sociologia das organizações: Uma Análise do Homem e das Empresas no ambiente Competitivo. São Paulo: Cengage Learning, 2009.

OLIVEIRA, Tuanny Kamila Braga. Desmotivação: um fator negativo na prática do professor. Revista Senso Comum, no 1, 2009, p. 76-85.Disponível em: http://radius.tachanka.org.Acessado em 27 de novembro de 2012.

PIOVESAN, Armando; TEMPORINI, Rita apud THEODORSON, G. A. \& THEODORSON, A. G.(1995). Pesquisa exploratória: procedimento metodológico para o estudo de fatores humanos no campo da saúde pública. Sítio Scielo Public Health <http://www.scielosp.org/scielo.php?pid=S0034-89101995000400010\& script =sci_arttext\&tlng=> Acessado em 17 de abril de 2013.

PRADO, M. E.B.B.. O uso do computador na formação do professor: um enfoque reflexivo da prática pedagógica. Publicado em www.proinfo.gov.br/biblioteca/publicações/livro14.pdef, 1993. Acesso em, 19.09.2014.

ROSA, Rosana Camilo da. A informática na educação: a experiência do Proinfo em Santa Catarina. Florianópolis: Curso de Pós-Graduação em Educação/UFSC, 2000. 117 p.(Dissertação de mestrado) 
SCHRUM, Lynne R. Tecnologia para Educadores - Desenvolvimento, Estratégias e Oportunidades - MEC 1. ed. Brasília: MEC/SEED/Proinfo, 1999.

SEBOK. Lou, Atlases published in the Netherlands in the rare atlas collection. Compiled and edited by Lou Seboek. National Map Collection (Canada), Ottawa. 1974

SETTE, Sonia Schechtman, et al. Formação de Professores em Informática na Educação: Um Caminho para Mudanças. Brasília: MEC/SEED/Proinfo, 1999.

TAKAHASHI, E.T. VALENTE, J.A.; BIANCHINI, S.M., FERRARI, J.O. e VANIN, V.A. Introdução a computadores, versão Experimental. Campinas: IMECC. UnICAMPI, 1976.

THEODORSON, G. A. \& THEODORSON, A. G.(1995). Pesquisa exploratória: procedimento metodológico para o estudo de fatores humanos no campo da saúde pública. Sítio Scielo Public Health $\quad<$ http://www.scielosp.org/scielo.php?pid=S0034-89101995000400010\& script =sci_arttext\&tlng=> Acessado em 17 de abril de 2010.

TORNAGHI, Alberto José Costa. Tecnologia da educação: ensinando e aprendendo com as TIC: guia do cursista/ Alberto José Costa Tornaghi, Maria Elisabette Brisola Prado, Maria Elizabeth Biancocini de Almeida. - 2 ed. - Brasília: Secretaria de Educação a Distância, 2010. 120 p.

VALENTE, J.A. . O Computador na Sociedade do Conhecimento. 1. ed. Campinas: Nied/Unicamp, 1999. 156p .

VASCONCELLOS, C.S. Avaliação da aprendizagem: práticas de mudanças por uma práxis transformadora. 5 ed. São Paulo: Liberdade, 2003.

VIGOTISKI, L. S. Pensamento e linguagem. São Paulo: Martins Fontes, $1987 .$.

VIGOTSKI, L. S. Psicologia pedagógica. Porto Alegre: Artmed,2003. (Trabalho original publicado em 1926)

Como citar este artigo (Formato ABNT):

LOPES, R.E.M.; VILALBA, O.A. O uso pedagógico do Programa Nacional de Tecnologia Educacional, nas Escolas Públicas Municipais. Id on Line Revista de Psicologia, Fevereiro de 2015, vol.9, n.25, p. 7-37. ISSN 1981-1189.

Recebido: 10/01/2015

Aceito:22/01/2015 